\title{
ANALISIS ANTHROPOMORPHISM DALAM DESAIN KARAKTER GIM ARKNIGHTS
}

\author{
Ika Resmika Andelina ${ }^{1}$ \\ Rike Souwandi ${ }^{2}$
}

Diterima Juli. 14, 2021; Disetujui November. 09, 2021

\begin{abstract}
Abstrak: Menara pertahanan adalah salah satu genre populer dalam dunia gim. Arknights adalah salah satu contohnya, namun selain genrenya, salah satu faktor yang mempengaruhi popularitas Arknights adalah desain karakternya yang unik. Didesain dengan gay a antropomorfisme moe anime, Arknights menciptakan variasi desain dengan ras fiksi baru yang menarik. Karakter merupakan salah satu elemen utama dalam game yang penting untuk menjalin hubungan dengan penggunanya. Dengan menggunakan desain karakter holistik Mounsey dan manga matriks, desain karakter antropomorfisme Arknights, penelitian ini mendapatkan hasil bahwa kemampuan karakter adalah elemen paling utama yang menjadikan sebuah karakter disukai, kemudian disusul dengan desain visual karakter yang menarik dan sesuai dengan kemampuan karakter.
\end{abstract}

Kata Kunci: antropomorfisme; desain karakter; gim; arknights

Abstract: Tower defense is one of the most popular genres in the game world. Arknights is one such example, but apart from the genre, one of the factors that influence Arknights' popularity is its unique character designs. Designed in the style of moe anthropomorphism, Arknights creates design variations with exciting new fictional races. Character is one of the main elements in the game that is important to build relationships with users. By using Mounsey's holistic character design and matrix manga, Arknights' anthropomorphic character design, this study finds that character abilities are the most important element that makes a character likable, then followed by an attractive character visual design in accordance with the character's abilities.

Keywords: anthropomorphism; character design; game; arknights

${ }^{1}$ Ika Resmika Andelina adalah adalah staf pengajar pada Fakultas Teknologi dan Desain Universitas Bunda Mulia (UBM) Ancol.

${ }^{2}$ Rike Souwandi adalah adalah mahasiswa pada Fakultas Teknologi dan Desain Universitas Bunda Mulia (UBM) Ancol. 


\section{Pendahuluan}

Gim sekarang ini adalah media hiburan, yang menempati tempat sendiri di hati konsumen. Gim adalah media interaktif dimana terdapat interaksi antara tampilan visual yang mewakili gim itu sendiri dengan penggunanya, dalam hal ini pemain. Pada interaksi ini, ketertarikan dan fokus pemain terhadap apa yang ditunjukkan oleh gim itu sendiri merupakan elemen yang penting, agar timbul pengalaman yang menyenangkan sehingga bisa mendorong pemain untuk terus bermain. Tampilan visual yang menarik dalam sebuah gim terdiri dari elemen visual seperti: desain karakter, objek, bentuk dan warna, juga animasi yang menggunakan prinsip-prinsip desain dan seni rupa (Putra \& Muhdaliha, 2017).

Menurut situs techcrunch pada 2019, gim seluler menjadi jenis aplikasi yang diunduh sebanyak 33\% dari total pengunduhan, dimana 74\% konsumen rela membayar demi memainkan sebuah gim seluler (Kaplan 2019). Sedangkan gim daring adalah gim yang terdiri dari mesin-mesin yang saling terhubung dengan jaringan yang dapat dimainkan, diakses oleh banyak orang. Sangat banyak sekali jenis gim daring yang ada, salah satu jenis gim daring yang populer adalah gim menara pertahanan (tower defense). Pada prinsipnya gim ini merupakan anak cabang dari gim berbasis strategi dimana para pemain meletakan benteng- benteng pertahanan untuk mencegah musuh berhasil menembus masuk ke dalam wilayah pemain. Gim jenis ini yang sempat populer adalah Plant VS Zombie (Baskoro, 2016).

Pada Mei 2019, Yostar, penerbit gim dari Cina, meluncurkan sebuah gim menara pertahanan bernama Arknights di Cina, dan rilis secara global pada Januari 2020, tanpa terduga Arknights menjadi populer dalam hanya kurun waktu satu tahun (Hikigaya, 2020). Beberapa situs gim internasional dan nasional menyebut- kan kepopuleran ini disebabkan oleh beberapa faktor, yakni: genre, cerita serta banyaknya jumlah karakter dengan desain anime-manga gaya antropomorfisme yang unik dan menarik, sehingga sistem transaksi mikro di dalam gim menjadi hal yang populer di kalangan para pemain Arknight, karena para pemain rela mengeluarkan uangnya untuk mendapatkan dan mengoleksi karakter-karakter favoritnya (Julianto, 2019; Rexan, 2020; Subari, 2020). Hal ini menjadikan karakter sebagai salah satu elemen yang selalu dipromosikan di dalam Arknights. Dalam dunia kreatif, hal seperti ini disebut dengan character merchandising. Menurut Verbauwede dalam Violeta (2020), character merchandising adalah sebuah adaptasi dan juga eksploitasi sekunder dari pemilik atau pencipta karakter fiksi bersangkutan, maupun pihak lain yang memiliki wewenang terhadap fitur-fitur penting pada identitas karakter fiksi tersebut (nama, gambar, desain, dan sebagainya).

Antropomorfisme sendiri adalah proses mengaitkan karakteristik, fitur, motivasi, niat, atau emosi mirip manusia dengan hal-hal yang bukan manusia (misalnya hewan, fenomena alam dan supernatural, benda, ataupun konsep abstrak). Penggunaan teknik antropomorfisme dengan desain yang tepat dan sesuai akan membuat sebuah desain dapat lebih diterima, dicintai dan disukai oleh konsumen (Delgado-Ballester et al., 2020). Sudah ada beberapa penelitian terdahulu mengenai antropomorfisme pada karakter, seperti yang dilakukan oleh Wahab dan Nugroho (2020), mereka melakukan penciptaan karakter satelit palapa dengan teknik antropomorfisme moe yang populer. Istilah moe sendiri muncul dari budaya populer Jepang, yaitu suatu hal (baik itu karakter dari game, komik, film animasi) yang bisa memunculkan rasa sayang dan suka, hal ini juga diperkuat dari kebudayaan masyarakat Jepang yang memang menganggap bahwa se- 
tiap benda memiliki roh, dan juga sifat masing-masing (Wahab, Nugroho, 2020). Namun, pendalaman lebih lanjut mengenai teknik antropomorfisme dalam suatu karakter gim, beserta elemen-elemen apa saja yang mempengaruhi dan digunakan pada penciptaan desain karakter belum terbahas secara lebih lanjut. Dalam penelitian ini, karakter pada gim Arknights akan dibedah dengan pendekatan teori karakter holistik milik Mounsey dan Manga Matrix untuk melihat elemen-elemen tersebut. Tujuan dari penelitian ini adalah untuk mengetahui apakah penggunaan teknik ini bisa membuat karakter dengan daya tarik yang lebih besar dan lebih dicintai oleh audiens gim jenis menara pertahanan, sehingga bisa menjadi referensi kajian dan pembelajaran bagi pihak industri ekonomi kreatif, serta pelaku desainer komunikasi visual, maupun pihak-pihak lain yang ingin menciptakan sebuah desain karakter yang menarik untuk menciptakan sebuah desain karakter untuk IP gim yang potensial dan unik, khususnya pada jenis menara pertahanan.

\section{Metode Penelitian}

Penelitian ini dilakukan dengan metode kualitatif komparasi dengan menganalisa karakter melalui desain karakter holistik milik Mounsey (Andelina 2020), yang kemudian secara visual diperdalam dengan membedah karakter menggunakan manga matrix, melalui tiga bagian matriks, yakni matriks bentuk, matriks kostum dan matriks kepribadian (Andelina 2021), terutama apa saja elemen antropomorfisme yang berpengaruh pada penciptaan desain karakter sampel. Matriks kepribadian akan dibedah dengan pendekatan desain karakter holistik (Andelina 2020), penjelasan akan dilakukan berdasarkan cerita di balik karakter, sifat karakter, audiens dan desain dari karakter itu sendiri. Desain karakter berkaitan erat dengan dua matriks lainnya, yakni matriks bentuk dan kostum. Visual karakter akan dianalisis lebih dalam berdasarkan dengan elemen pembentuk sifat karakter yakni ekspresi muka, penampilan dan aksesoris, gestur dan bentuk, serta warna dan komposisinya. Diperdalam dengan pendekatan intertekstualitas, dimana konsep dasar suatu karakter akan dikaitkan dengan hal-hal (berupa teks) diluar visual karakter itu sendiri namun tetap memiliki keterkaitan dalam konsep, lalu kemudian hasilnya akan dibandingkan satu sama lain. Karakter sampel dipilih berdasarkan hasil voting karakter populer pada server Global dan Cina pada ulang tahun kedua Arknights (All Operators Popularity Ranking-Issue 6 [2nd Anniversary Version] 2020), dimana karakter Silver Ash masih menduduki peringkat 4 walau sudah rilis sejak tahun 2019, sedangkan karakter Thorn berada pada peringkat 3 semenjak kemunculannya pada tahun 2020 lalu.

\section{Hasil dan Pembahasan}

\section{Desain Karakter}

Pada desain karakter Arknights, ciri khas dari karakter operator adalah penggunaan teknik Antropomorfisme. Definisi dari antropomorfisme: proses mengaitkan karakteristik, fitur, motivasi, niat, atau emosi mirip manusia dengan hal-hal yang bukan manusia (misalnya hewan, fenomena alam dan supernatural, benda, ataupun konsep abstrak). Teknik ini tidak hanya menghubungkan kehidupan (animisme) dengan sesuatu yang tidak hidup tetapi juga mempersepsikan objek nonmanusia sebagai "seperti kita" dengan memberikannya hal-hal seperti manusia seperti, kepribadian, karakteristik dan pikiran dan sebagainya (Delgado-Ballester et al., 2020). Wahab dan Nugroho juga menyatakan bahwa adanya istilah yang disebut dengan antropomorfisme moe yang populer dengan budaya pop kultur Jepang, teknik ini dapat menim- 
bulkan rasa sayang, suka dan cinta terhadap suatu karakter. Teknik ini sesuai dengan target konsumen remaja, yang juga merupakan konsumen dari gim Arknights (Wahab, Nugroho, 2020).

Mounsey dalam Andelina (2020) menyatakan bahwa dalam desain Holistik terdapat 4 faktor agar karakter menjadi dicintai, yakni: cerita di balik karakter, sifat karakter, kualitas pemasaran dari karakter serta desain visual dari karakter itu sendiri. Menurutnya, cerita di balik karakter adalah hal yang paling penting, baru kemudian sifat karakter, yang disesuaikan dengan karakteristik audiens yang dituju dengan cara melihat kecenderungan yang ada di pasar, lalu diperkuat dengan desain visual dari karakter itu sendiri, dalam hal ini kekuatan visual dari karakter Arknights adalah karakter yang di desain dengan Antropomorfisme moe. Hal ini kemudian diperkuat dengan apa yang disimpulkan oleh Haryanto, Yessica dkk dalam Andelina (2020) mereka menyebutkan bahwa sebuah karakter harus memiliki kepribadiannya sendiri agar dapat menjadi menarik dan lebih hidup. Unsur-unsur pembentuk kepribadian karakter yang terdapat di penelitian mereka antara lain adalah ekspresi wajah, penampilan dan aksesoris, serta bentuk dan gestur tubuh lalu warna dan juga komposisinya.

\section{Manga Matrix}

Andelina (2021) menggunakan pendekatan Manga Matrix yang dikemukakan oleh Tsukamoto untuk mengkaji karakter dengan referensi tidak terbatas. Metode ini dibagi menjadi tiga matriks utama, yakni: Matriks bentuk, Matriks kostum dan Matriks kepribadian.

\section{Analisa Karakter 1: SilverAsh (En- ciodas)}

Silver Ash berasal dari ras Feline, nama aslinya adalah Enciodas. Pria dengan tinggi $192 \mathrm{~cm}$ ini merupakan panglima perang (Warlord) ternama yang berasal dari Kjerag, sebuah negara bersalju yang memiliki julukan "Snow Realm". Silver Ash sendiri pada aslinya merupakan kode nama yang berasal dari nama klan/keluarganya, dan Enciodas merupakan pemimpin keluarga Silver Ash yang sekarang. Enciodas juga merupakan pemimpin dari Karlan Trade CO., LTD, perusahaan trading nasional Kjerag yang bertanggung jawab terhadap roda perekonomian Kjerag dan dunia luar. Enciodas juga memiliki hewan peliharaan, yakni seekor burung elang abu-abu kehitaman yang dinamakan Tenzin yang dapat dilihat pada Gambar 1.

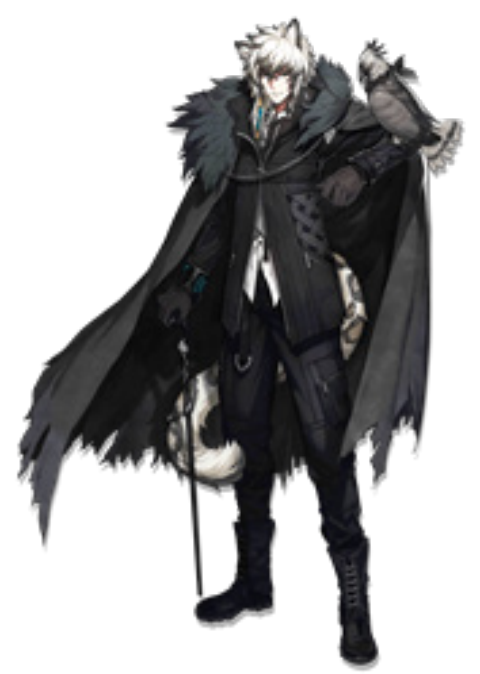

Gambar 1. SilverAsh dan Tenzin (Sumber: https://gamepress.gg/)

Enciodas digambarkan sebagai pecinta dan kolektor literatur dan seni yang juga sangat ahli dalam strategi. Ia juga seorang ahli berpedang dengan pengalaman bertempur 4 tahun. Walaupun memiliki latar belakang pendidikan bangsawan kuno di keluarganya, pola pikir Enciodas lebih ke arah modern, dan ia juga selalu mencoba menentang tradisi-tradisi yang dianggap kolot dengan memasukkan pengetahuan 
dan pendidikan modern ke dalam keluarganya, karena itulah ia menjadi sosok yang kontroversial di Kjerag.

Masa lalu Enciodas tidak bisa dikatakan baik, kedua orang tuanya meninggal di tangan lawan mereka dalam permainan politik klan, namun karena garis keturunan Silver Ash yang mulai berkurang dengan cepat, hal ini akhirnya diabaikan. Kejadian ini membuat Enciodas tumbuh menjadi sosok yang tenang, berpendirian, kuat dan selalu berusaha melindungi kedua adiknya, Paraminx dan Cliffheart, hingga kedua adiknya bisa mandiri. Setelah itu akhirnya ia pergi dari Kjerag untuk mengenyam pendidikan modern. Di saat yang sama, ia membiarkan lawan-lawan politiknya di dalam klan saling berkonflik satu sama lain tanpa ia harus ikut campur. Sepulang dari studinya, Enciodas mereformasi dan membangun ulang klan Silver Ash yang mulai hancur dan juga Kjerag dengan menciptakan Karlan Trading serta mengubah banyak peraturan -peraturan lama. Setelah itu, Karlan Trading dengan cepat bangkit dan berhasil memonopoli di sejumlah besar industri modern yang sebelumnya dilarang di Kjerag. Dengan mengekspor barang dan bahan mentah ke negara lain dan mengimpor produk industri modern, Enciodas berhasil mengumpulkan kekayaan yang besar dalam waktu yang sangat singkat, dan keberhasilan perusahaannya mengembalikan nama Keluarga Silver Ash ke posisinya di parlemen Kjerag. Namun, karena konspirasi politik, dua adik Enciodas sama-sama mengalami peristiwa yang akan berdampak besar pada keluarga Silver Ash: Pramanix dibaptis sebagai Kjerag Saintess dalam ritual keagamaan, dan Cliffheart terinfeksi Oripathy. Karena hal-hal ini, hubungan Enciodas dengan adik-adiknya menjadi sedikit renggang, walau pada aslinya Enciodas masih sangat memperhatikan kedua adiknya.

Dari narasi pembicaraan antar pemain dengan operator lain, dapat dilihat banyak operator yang sungkan terhadap Enciodas, hal ini dikarenakan latar belakang Enciodas yang merupakan bangsawan dan juga tokoh paling berpengaruh di Kjerag. Bahkan tak jarang banyak yang bingung serta mempertanyakan alasan Enciodas membawa adik dan rekan-rekannya di Karlan Trading untuk bergabung dengan pemain, karena dianggap tidak akan memberikan keuntungan apapun untuk Enciodas. Namun, dilihat dari teks percakapan yang terjadi antar Enciodas dan Dokter (pemain), terlihat bahwa Enciodas menaruh ketertarikan dan perhatian yang cukup besar kepada Dokter, beberapa teks pembicaraan dan juga keterangan dalam gim menyatakan bahwa Enciodas menganggap pemain sebagai seorang teman baik yang juga layak dijadikan rival. Sejauh ini hanya hal-hal inilah yang diketahui mengenai cerita dan latar belakang Enciodas, karena ia belum memiliki sama sekali cerita sampingan yang menceritakan lebih lanjut mengenai dirinya walau ia termasuk karakter yang dikeluarkan di awal-awal peluncuran gim Arknights.

Berdasarkan desain visualnya, secara karakterisitik tubuh Enciodas merupakan karakter manusia dengan tambahan elemen dari hewan Snow Leopard (macan tutul salju). Hal ini dapat dilihat dari bentuk telinga, ekor, serta warna rambut yang digambarkan menyerupai snow leopard. Selain tampilan visual, kebiasaan-kebiasaan yang dilakukan oleh snow leopard juga diadopsi pada karakter Enciodas. Hal ini ditampilkan pada spin off berupa komik official Arknights. Kebiasaan yang dilakukan pada komik ini antara lain, mood karakter yang tergambar secara ekspresif pada pergerakan telinga dan ekor Enciodas yang dapat dilihat pada Gambar 2.

Kesamaan lain antara Enciodas dengan macan tutul salju adalah kelangkaan yang ada pada keluarga keduanya, sama seperti cerita latar belakang Enciodas, 


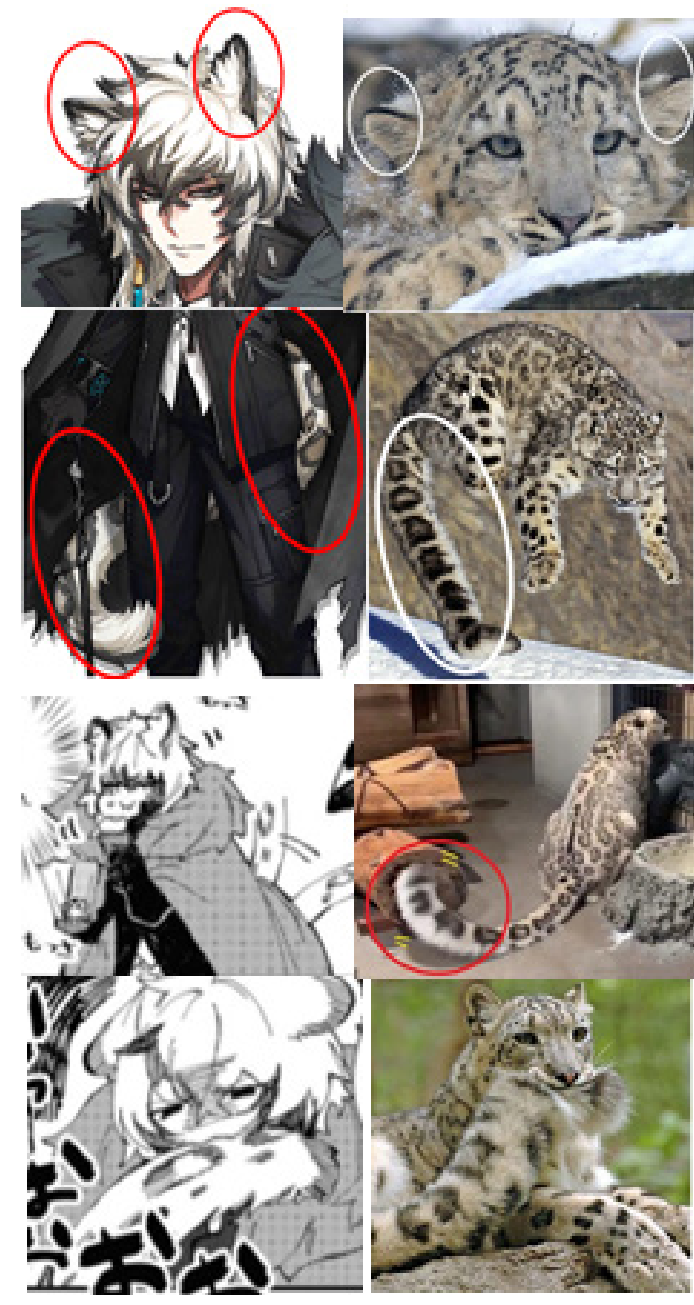

Gambar 2. Siver Ash dan Macan Tutul Salju (Sumber: Data Pribadi)

macan tutul salju adalah hewan langka dilindungi yang sudah mulai sangat sedikit jumlahnya, kurang dari 10.000 ekor macan tutul salju dewasa, dan diprediksi akan turun menjadi hanya 10\% dari jumlah sekarang pada tahun 2040 jika perburuan dan perusakan habitat mereka terus berlangsung.

Untuk kostum yang akan dianalisis di sini adalah kostum bawaan karakter (bukan skin outfit) yakni kostum awal dan kostum setelah evolusi menjadi elite 2 (kostum elite 1 sama dengan basic costume) pada Gambar 3.

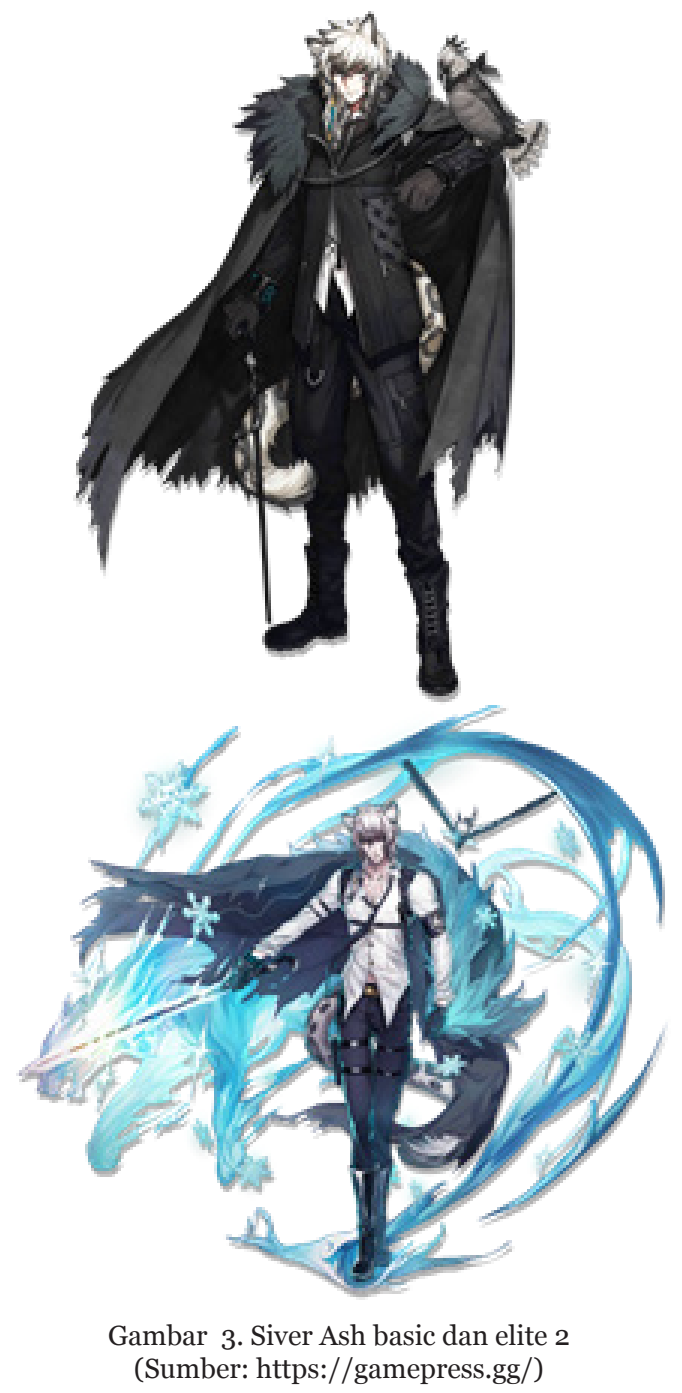

Pada kostum basic, di bagian luar Enciodas menggunakan mantel hitam dengan panjang selutut dengan bulu-bulu berwarna abu-abu gelap kehitaman, yang diikat dengan rantai perak di bagian kerah, pada bagian bawah tampak ada banyak bekas robekan. Di dalam mantel terdapat kemeja putih dan dasi hitam yang tertutup coat hitam panjang dengan aksesoris sabuk dan juga beberapa resleting. Menggunakan celana hitam tipe cargo, yang dihiasi beberapa kantong dengan resleting dan juga sabuk. Alas kaki berupa sepatu boots hitam sebetis dengan tali 
yang terikat rapi. Aksesoris rambut dari bebatuan permata yang didekorasi oleh tassel (rumbai), sepasang sarung tangan hitam dengan gelang hitam beraksen warna biru pada tangan kanannya. Senjata yang digunakan Enciodas adalah tongkat berujung lancip. Tongkat ini tampak seperti tongkat bantu jalan, namun pada saat pertempuran Enciodas meng- ayunkan ke depan tongkat ini untuk menyerang musuh baik dari jarak dekat maupun jauh.

Pada elite 2, mantel tetap ada, namun dibuka dan dipegang dengan satu tangan. Coat hitam tidak digunakan lagi. Kemeja putih lengan panjang tetap ada tapi tidak rapi (tidak terkancing pada bagian atas dan bagian bawah kemeja tidak dimasukkan), demikian juga dengan dasi hitam. Celana cargo digantikan oleh celana kain bahan hitam, dengan sabuk hitam dengan kepala sabuk berwarna emas. Bagian bawah celana dimasukkan ke dalam alas kaki yang kini menjadi boots hitam di bawah lutut tanpa tali. Terdapat arm band berlogo Kjerag di tangan kirinya, holster dada untuk menyimpan belati di sebelah kiri, dan di kedua pahanya. Untuk hiasan rambut, sarung tangan dan tongkat, tidak mengalami perubahan.

Secara keseluruhan basic costume Ecinodas terlihat rapi dan tampak seperti orang dengan latar belakang berada dan berpendidikan. Sedangkan, pada elite 2-nya kesan yang muncul lebih terlihat berantakan dan urakan, namun penambahan beberapa holster senjata merubah kesan itu menjadi ke arah yang lebih berbahaya.

Secara gestur, terdapat perbedaan yang cukup mencolok. Pada basic, Enciodas digambarkan tengah berdiri dengan pakaian rapi dan lengkap, serta membawa Tenzin yang bertengger di tangan kirinya, sementara tangan kanan Enciodas memegang tongkat. Gestur terbuka dengan kedua tangan yang berada di samping badannya (tidak menutupi daerah dada atau perut), kedua kaki membuka dengan ukuran yang kurang lebih sama dengan lebar bahu. Kuping dan ekor juga dalam kondisi normal. Pada versi elite 2, gestur mengalami perubahan, kini tangan kanannya menghunuskan tongkat sambil mengeluarkan kekuatan es, tangan kiri membuka mantel dengan memegang bagian bulu pada mantel. Tenzin tampak terbang siaga di sisi kanan Enciodas. Posisi kaki saling menyilang seperti sedang berjalan maju, gestur ini tampak seperti sedang bersiaga atau bersiap untuk maju ke medan pertempuran. Bila pada gestur basic kesan tenang dan mewah terlihat menonjol, maka pada elite 2 kesan berbahaya lebih ditonjolkan. Secara ekspresi, tidak ada perbedaan ekspresi signifikan di antara keduanya, seperti yang dapat dilihat pada Gambar 4. Keduanya masih terlihat tenang dan berkepala dingin, walau pada elite 2 ekspresinya tampak lebih sedikit siaga (alis yang lebih menekuk), posisi kuping masih tetap normal, namun bagian ekor terutama ujung ekor tampak lebih mengembang, menandakan kesiagaan.
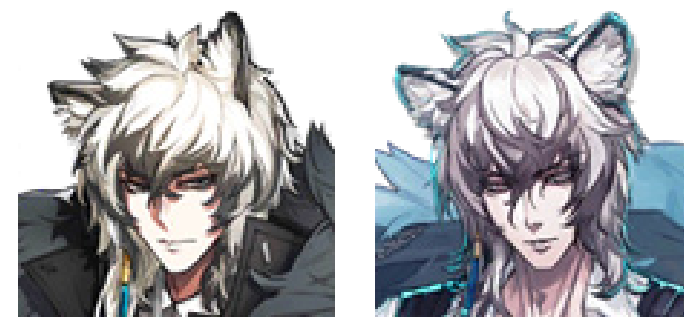

Gambar 4. Ekspresi basic dan elite 2. ( Sumber: https://gamepress.gg/)

Secara keseluruhan, gestur dan ekspresi visual sesuai dengan sifat dan deskripsi karakternya yang tenang, dewasa, tenang, berpikir rasional namun kuat dan berbahaya. Tone warna fisik dari karakter secara keseluruhan mencerminkan warna-warna dari macan tutul salju, yakni abu-abu dengan sentuhan sedikit spot hitam seperti warna bulu macan tutul salju. Sedangkan tone warna 
dari kostum karakter adalah tone warna macan tutul salju yang dibalik, yakni mayoritas hitam dengan sentuhan sedikit abuabu tua.

Dari kemampuan karakter, SilverAsh masuk di kelas Ranged Guard yang memiliki spesialisasi dalam DPS dan support. Sebagai ranged guard, Enciodas memiliki serangan jarak jauh dengan jangkauan paling luas di antara seluruh karakter operator, ia juga dapat menarget musuh yang terbang di udara, walau hanya dengan 80\% kekuatan ATK-nya. Enciodas memiliki statistik kemampuan dan kekuatan yang bagus, menjadikannya salah satu karakter tipe Guard terbaik dan terkuat di gim Arknights. Walau cerita mengenai Enciodas sendiri belum banyak terkuak selain dari archieves karakter, Enciodas mendapat sambutan tinggi dari para pemain. Hal ini juga didukung oleh kemampuan Enciodas sebagai seorang operator. Sampai saat ini, posisinya sebagai karakter favorit dan berguna belum bergeser dari 5 besar walau ia sudah dirilis sejak awal kemunculan gim. Kemampuannya ini membuat Enciodas menduduki peringkat S (Super) yang merupakan tingkatan tertinggi sebuah karakter, dan masih banyak pemain yang ingin mendapatkannya.

\section{Analisa Karakter 2: Thorns}

Thorns dari ras Aegir adalah seorang pejuang garis depan untuk Rhodes Island. Pria dengan tinggi $177 \mathrm{~cm}$ ini memiliki pengalaman bertempur 5 tahun, menjadikannya operator yang handal. Thorns lahir di pedalaman Iberia, namun meninggalkan kampung halamannya saat terjadi perselisihan agama setempat. Setelah meninggalkan wilayah Iberia, ia diundang untuk bergabung dengan Rhodes Island. Ketika Thorns pertama kali bergabung dengan Rhodes Island, gaya bertarungnya di medan pertempuran memberi kesan bahwa ia adalah sosok yang acuh tak acuh, bahkan

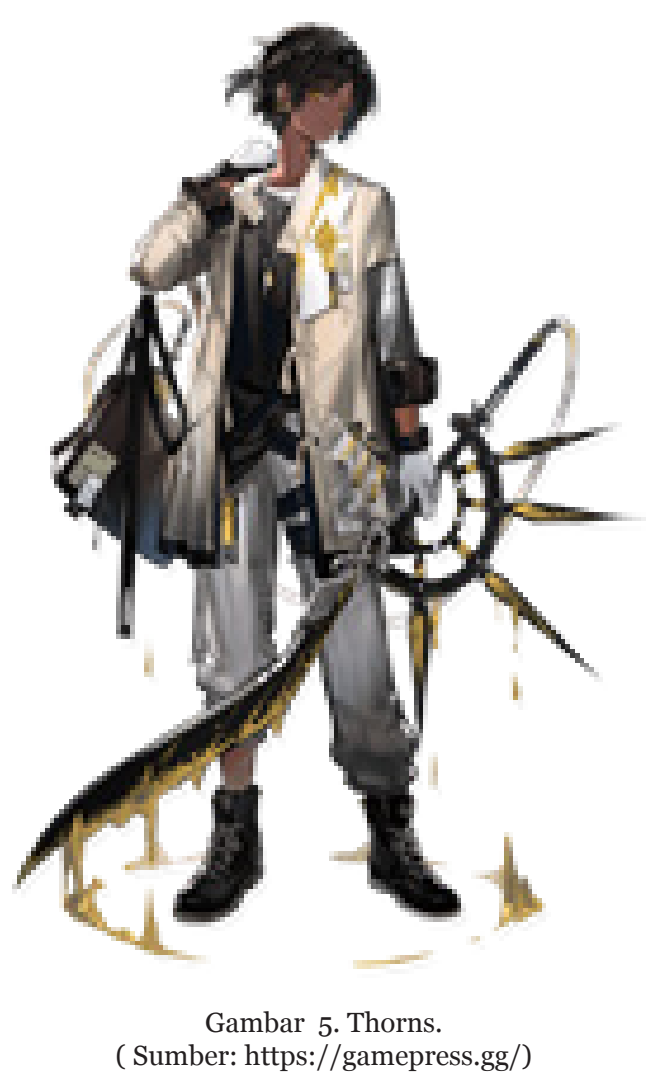

cenderung kejam kepada orang lain. Namun setelah mengenal Thorns lebih lanjut, semua orang secara bertahap menyadari bahwa walau sikap Thorns tampak dingin dengan gaya berbicara yang blakblakan, sifat aslinya termasuk lugas, berjiwa bebas dan cukup ramah meskipun tidak berlebihan. Bagi Thorns, persepsi orang dan cara dunia luar menilainya tidak memiliki pengaruh apapun padanya.

Thorns sangat berbakat dalam bidang farmakologi dan juga berpedang. Dalam farmakologi, ia sangat ahli dalam mengekstraksi serta memurnikan senyawa obat, terutama racun. Selain itu, Thorns juga selalu memiliki ide yang lebih berani dalam eksperimen, ia menikmati melakukan eksperimen walau kerap menemui kegagalan. Bila sedang fokus melakukan eksperimen Thorns sering melupakan hal lainnya, seperti mer- 
awat dirinya sendiri. Lupa memakai jaket, salah satu kaki celana tergulung, memakai baju yang berlubang bahkan terbalik, rambutnya terbakar atau mengembang tak karuan karena eksperimen adalah halhal yang biasa terjadi. Bagi Thorns yang memang mengutamakan efisiensi dan presisi, mengurus penampilan baginya hanyalah membuang waktu saja. Selain bidang farmakologi, kemampuan Thorns dalam berpedang juga sudah tidak diragukan lagi. Gaya berpedangnya sangat cepat dan membuthkan akurasi serta presisi yang tinggi, di Iberia gaya berpedang ini dikenal sebagai "Destreza", namun, walau gaya ini terkenal di penjuru Iberia, tidak semua orang bisa menguasainya karena teknik ini tidak hanya membutuhkan kebugaran fisik yang sangat baik, tetapi juga memiliki persyaratan yang sangat menuntut untuk pikiran pengguna.

Dengan kombinasi ilmu berpedang dan juga racun ampuh buatannya sendiri, Thorns kerap berhasil menyelesaikan misi dengan hasil maksimal dan kerusakan yang minim, walau caranya yang berkesan dingin dan efisien, pada banyak situasi caranya ini menerima banyak kritik. Banyak operator berkomentar bahwa Thorns sulit bergaul, walaupun begitu operator-operator ini ternyata masih berinteraksi dan berteman cukup baik dengan Thorns. Operator-operator yang lebih bisa melihat dan menerima sisi negatif Thorns pada akhirnya menjadi dekat dengannya.

Hubungan Thorns dengan Dokter tidak buruk, tapi juga tidak terlalu spesial. Pada dialog yang terjadi antara Thorns dan Dokter, dapat dilihat bahwa Thorns menaruh hormat dan peduli namun tidak secara berlebihan seperti beberapa operator lain. Ia juga beberapa kali menceritakan pada Dokter mengenai dirinya, masa lalu, serta negara asalnya. Pada satu percakapan, Thorns menganggap gaya berpedangnya sama dengan gaya strategi dan kepemimpinan pemain yang efisien dan taktis. Pada salah satu side story, dijelas- kan Thorns tidak memiliki perasaan lebih spesial terhadap latar belakang rasnya, Thorns juga tidak menyukai sesama ras Aegir yang tidak berusaha menyembunyikan jati dirinya serta tidak segan menganggap mereka musuh.

Berdasarkan desain visualnya, Thorns merupakan salah satu dari sedikit operator yang sangat menyerupai manusia biasa, hal ini dikarenakan ras Aegir memang melakukan penyamaran agar dapat membaur dengan sekitarnya terkait dengan masa lalu mereka. Antropomorfisme dari Thorns sendiri terinspirasi dari hewan sea urchin (bulu babi/landak laut), walau dari bentuk fisik, tidak terdapat elemen-elemen fisik bulu babi yang terbentuk secara khusus di tubuh Thorns. Elemen bulu babi yang diadaptasi pada visual Thorns adalah tone warna dari bulu babi, yakni: warna hitam, coklat, broken white dengan sentuhan keabu-abuan, dan juga kuning kunyit. Warna-warna ini kemudian dipakai untuk warna rambut (hitam), mata (kuning kunyit), kulit (coklat), pakaian (broken white dengan sentuhan abu-abu), aksesoris (kuning kunyit, kuning, hitam), hingga warna senjata dan racun (hitam dan kuning kunyit) yang selalu digunakan pada senjatanya.

Antropomorfisme bentuk yang paling terlihat adalah pada saat Thorns mengeluarkan kemampuannya di pertempuran, dia akan membentuk lapisan pelindung bulat transparan yang memiliki duri-duri hitam kekuningan di sekelilingnya yang bisa ditembakkan layaknya bulu babi. Thorns juga memiliki daya regenerasi yang kuat dalam pertempuran, ini juga merupakan salah satu hal yang dimiliki oleh bulu babi. Selain itu, nama Thorns juga memiliki makna duri, sama seperti duri yang terdapat pada cangkang luar bulu. Keahlian Thorns dalam mengolah racun juga berkaitan dengan bulu babi yang memang hewan beracun seperti yang dapat dilihat pada Gambar 6. 

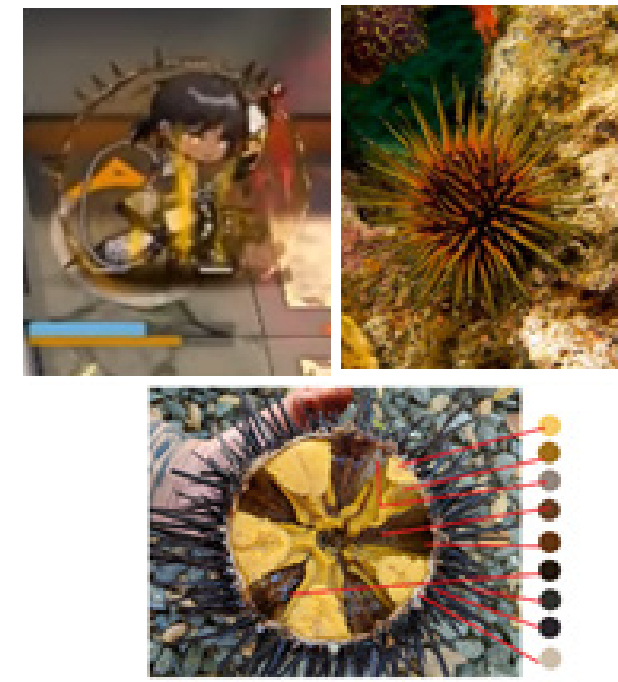

o우우웅
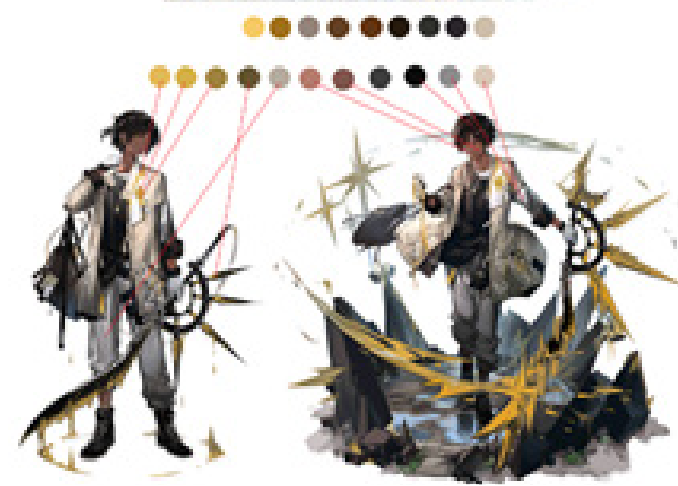

Gambar 6. Thorns mengeluarkan kemampuannya serta perbandingan tone warna Thorns dan Bulu Babi (Sumber: Data Pribadi)

Kostum yang akan dianalisis di sini adalah kostum bawaan karakter yakni kostum awal dan kostum setelah evolusi menjadi elite 2 (kostum elite 1 sama dengan basic) dapat dilihat pada Gambar 7.

Pakaian paling luar Thorns berdasarkan dari coat medis dengan modifikasi pada gaya kancing, kerah, ujung lengan baju serta kantung untuk vial racun dan obat-obatan. Pola coat merupakan garis miring menyilang, dengan warna krem keabu-abuan. Pada bagian dalam, Thorns menggunakan kaos hitam dan putih, 2 kaos ini dipakai secara berlapis, dengan kaos berwarna putih ada di bagian dalam, ini persis seperti cangkang bulu babi yang berwarna hitam di luar dan putih di

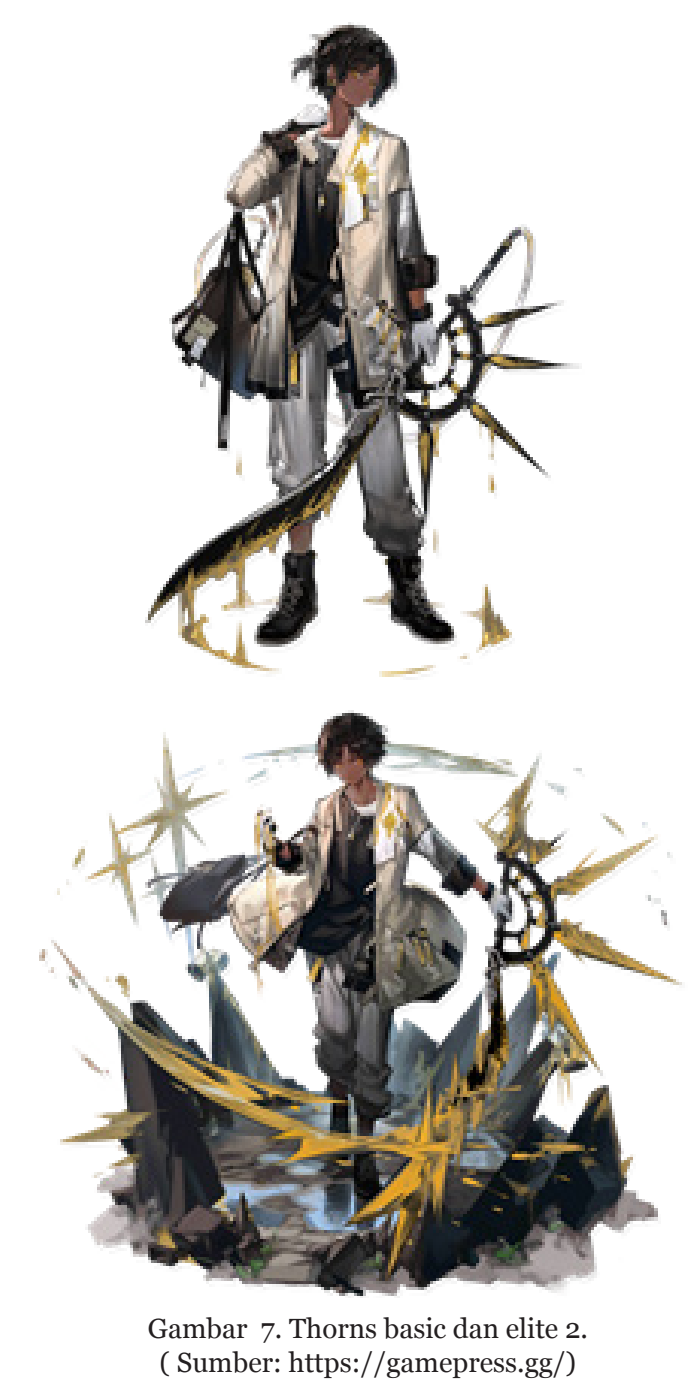

dalam. Kaos berwarna hitam dibiarkan masuk setengah ke dalam celana dan setengah lagi keluar tak beraturan. Celana yang digunakan adalah celana bahan kain longgar berwarna abu-abu dengan motif garis lurus, dipakai dengan sebelah tergulung dan satu kaki lagi masuk ke dalam sepatu boots. Ia menggunakan boots hitam dengan tali berwarna putih yang terikat tidak sampai bagian atas dan tersimpul dengan cukup rapi. Terdapat dua buah anting gaya clip pada telinga kanannya (1 hitam, 1 abu-abu), kalung dengan dua buah bandul, salah satunya berbentuk kotak berwarna kuning emas, 
dan satunya berbentuk pedang dengan warna abu-abu. Thorns menggunakan sarung tangan berwarna putih dengan aksen hitam. Ia juga menggunakan pin berwarna emas di bagian dada pada coat-nya. Senjata Thorns merupakan pedang melengkung Scimitar yang dikombinasikan dengan chakram setengah lingkaran yang berduri. Ujung senjatanya terdapat selang transparan yang berujung pada kantung berisi racun yang dibawa Thorns pada tas bahu di tangan kirinya, racun akan dipompa dan dialirkan dari tube racun sehingga muncul dari bagian tajam senjatanya. Selain tube racun di tas hitam yang dibawa oleh Thorns, terdapat pula beberapa vial berisikan racun di kantong jubah medisnya dan juga di holster paha kirinya. Tidak ada perubahan kostum pada kostum elite 2 Thorns. Yang mengalami perubahan sedikit kini ujung kedua celana Thorns digulung, serta penampakan senjata yang mengeluarkan racun lebih banyak.

Sedangkan secara gestur, terdapat perbedaan yang cukup mencolok. Pada basic, Thorns digambarkan berdiri dengan pose berdiri yang berkesan cuek dan santai. Gestur Thorns tidak terlalu terbuka atau pun tertutup dengan satu tangan memegang tali tas dan terarah ke arah leher dan tangan lain berada di samping dan memegang senjatanya. Kepala Thorns tampak sedang mengangkat dagu ke atas, seakan melihat sesuatu hal yang lebih kecil darinya, kemudian kedua kaki membuka dengan ukuran yang kurang lebih sama dengan lebar bahu. Pada versi elite 2, tangan kanannya kini tampak mengayunkan senjatanya dengan volume racun yang semakin banyak. Tangan kiri memegang cairan racun yang sedang mengalir jatuh ke bawah (bila dilihat ada visual botol yang pecah, tampaknya Thorns meremukan botol itu dengan tangan kirinya), tali tas kini disampirkan di lengan kiri atas. Posisi kaki seperti sedang berjalan maju, dengan coat yang berkibar. Gestur ini tampak lebih berbahaya dan sedang bersiaga, hendak maju untuk melawan mu- suhnya. Bila pada gestur basic kesan cuek dan urakan terlihat menonjol, maka pada elite 2 kesan berbahaya lebih ditonjolkan.

Secara ekspresi yang dapat dilihat pada Gambar 8, ada perbedaan cukup signifikan di antara keduanya, pada basic, muka Thorns lebih berkesan meremehkan dan sombong (melihat dengan mengangkat dagu), sedangkan pada elite 2 ekspresinya tampak lebih siaga (alis yang lebih menukik tajam dengan pose dagu yang lebih ditekuk ke dalam).
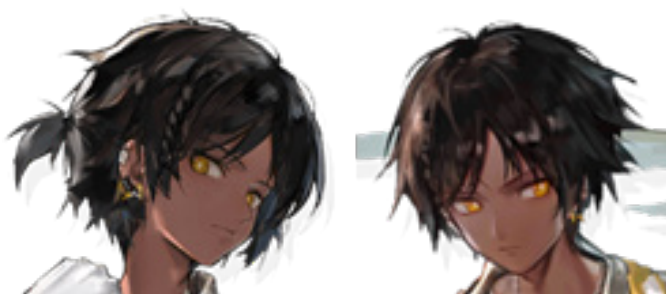

Gambar 8. Ekspresi Thorns.

(Sumber: https://gamepress.gg/)

Secara keseluruhan, gestur dan ekspresi visual, sesuai dengan sifat dan deskripsi karakternya yang cuek, efisien, tidak berpikiran akan pendapat orang lain, dan juga kuat serta berbahaya. Tone warna fisik dan kostum dari karakter secara keseluruhan juga mencerminkan warna-warna dari hewan bulu babi, yakni tone hitam, coklat, broken white dengan sentuhan krem dan abu-abu, warna kuning kunyit. Warna-warna ini seperti warna cangkang luar, dalam dan organ isi bulu babi.

Sedangkan dari kemampuan karakter, Thorns masuk di kelas ranged Guard yang memiliki spesialisasi dalam pertahanan diri, kerusakan berjangka panjang, DPS jarak jauh terutama untuk melawan musuh jarak jauh. Pada saat mengaktifkan kekuatannya, Thorns akan masuk ke dalam mode serang balik, dimana ia mendapatkan bonus ATK dan DEF dan ketika diserang akan menembakkan duri-durinya ke beberapa musuh dalam jarak yang lebih jauh, jadi memungkinkan untuk menaruh Thorns dalam mode 
bertahan jika diinginkan. Kemampuan ini membuatnya menjadi operator yang sangat fleksibel, menjadikannya sebagai salah satu operator paling serbaguna dalam gim. Kemampuan ini membuat karakter Thorns menjadi incaran banyak pemain walau baru ada dua side story mengenai dirinya. Sampai saat ini, posisi Thorns sebagai karakter belum bergeser dari peringkat kegunaan karakter walau ia sudah dirilis sejak 8 November 2020 di server China dan Januari 2021 di server global. Kemampuannya yang kuat membuat Thorns masih menduduki peringkat $\mathrm{S}$ (Super) yang merupakan tingkatan tertinggi sebuah karakter, dan masih banyak pemain yang ingin mendapatkannya seperti yang dapat dilihat pada Gambar 9.

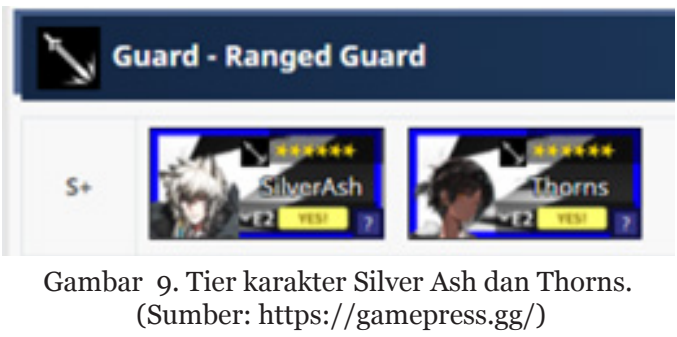

\section{Hasil Analisis Keseluruhan}

Teknik antropomorfisme yang dipakai pada sampel karakter menggunakan konsep dasar yang ada, yakni mengaitkan karakteristik, fitur, motivasi, niat, atau emosi mirip manusia dengan hal-hal yang bukan manusia. Selain hal-hal di atas, latar belakang dari hewan yang dijadikan landasan antropomorfisme juga dipakai dalam latar belakang cerita karakter. Hal ini bisa dilihat di latar belakang cerita klan Silver Ash yang sama dengan Snow Leopard yang ternyata bisa menimbulkan keterkaitan khusus dengan pemain, sehingga membuat pemain tergerak untuk melakukan tindakan untuk membantu snow leopard yang sebenarnya. Hal ini dapat dilihat dari projek kolaborasi bertajuk Coexistance yang dilakukan Arknights dengan WWF, dengan menggunakan kel- uarga Silver Ash sebagai dutanya seperti pada gambar 10, Arknights mengadakan kampanye pengumpulan dana melalui pembelian dalam gim, yang kemudian digunakan untuk konservasi macan tutul dan habitatnya. Program ini mendapat respon yang sangat positif dari para pemain (Arknights Official Youtube).
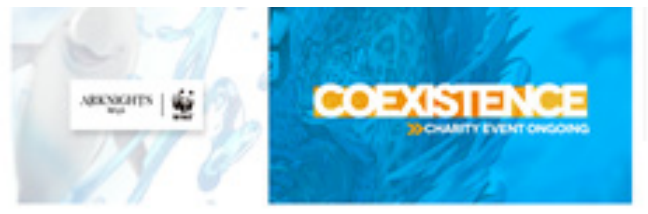

Arknights Partners with WWF to Raise Awareness for iconic species under threat
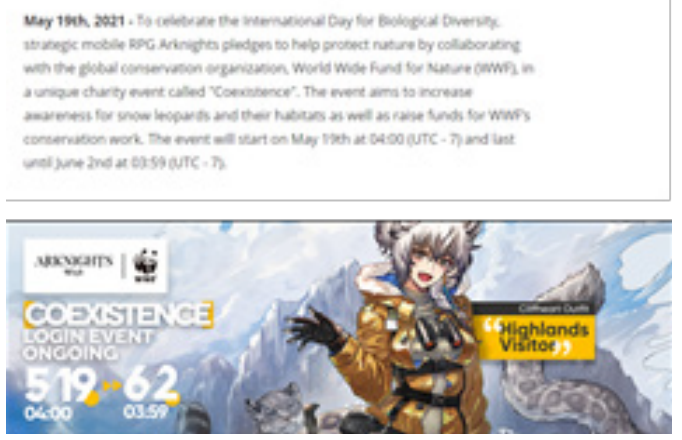

Gambar 10. Pengumuman event kolaborasi dengan WWF.

(Sumber:https://www.gamespress.com/ArknightsPartners-with-WWF-to-Raise-Awareness-for-iconicspecies-unde)

Sementara pada karakter Thorns, teknik antropomorfisme yang dipakai lebih ke arah penggunaan karakteristik non fisik, seperti kemampuan perlindungan diri, kemampuan regenerasi, kemampuan mengolah racun. Segi fisik hanya diadaptasi berdasarkan tone warna bulu babi yang kemudian diaplikasikan kepada desain karakter seperti warna fisik dan kostum. Cara adaptasi ini lebih tidak umum dibandingkan teknik antropomorfisme pada umumnya, dapat dilihat dari karakter-karakter lain pada gim Arknights. Dari hampir 167 karakter operator yang ada, karakter dengan pendekatan antropomorfisme seperti Thorns tidak sampai $3 \%$ dari total keseluruhan 
karakter operator. Sempat terjadi perdebatan mengenai hewan asli Thorns juga di kalangan fans, sampai Yostar akhirnya memberikan klarifikasi bahwa Thorns memang berasal dari bulu babi.

Penggunaan gaya anime-manga di sini juga digunakan karena gaya itu sudah menjadi salah satu bagian pop kultur dunia yang sudah memiliki pangsa pasarnya sendiri, namun, berbeda dengan pernyataan yang dikemukakan oleh desain karakter holistik Mounsey, pada Arknights cerita bukan merupakan faktor utama yang membuat Enciodas dan Thorns disukai oleh pemain. Faktor kegunaan dan kekuatan mereka di dalam misi dan membuat level permainan menjadi lebih mudah atau terselesaikan dengan baik merupakan faktor utama kenapa Enciodas dan Thorns menjadi karakter kesukaan pemain.

Berdasarkan hasil penarikan data di atas, teknik antropomorfisme memang masih sering digunakan sesuai dengan gaya pop kultur yang populer sekarang. Teknik penggunaan teknik antropomorfisme yang dipakai pada sampel karakter masih menggunakan konsep dasar yang ada. Namun pendekatan yang dipakai oleh kedua karakter berbeda, (1) ada dua macam pendekatan yang digunakan pada karakter sampel pada Arknights, yakni pendekatan dengan penambahan karakteristik pada fisik karakter seperti Silver Ash, atau tanpa penambahan fisik karakter seperti Thorns. (2) pendekatan antropomorfisme pada gim Arknights tidak hanya terkait dengan karakteristik, fitur, motivasi, niat, atau emosi belaka, tapi juga menggunakan latar belakang atau cerita yang ada di hewan yang menjadi inspirasi utamanya, hal ini juga bisa membawa kedekatan dan pengetahuan baru dari pemain dengan hewan aslinya, seperti pada hewan macan tutul salju. (3) Pada gim menara pertahanan seperti Arknights para pemain lebih mengutamakan kemampuan karakter bila dibandingkan dengan desain dan cerita karakter karena akan memudahkan permainan. Hal ini membuat teori Holistik milik Mounsey yang menyatakan bahwa elemen nomor utama dari karakter yang dicintai menjadi tidak terbuktikan di gim Arknights. Elemen-elemen itu masih menjadi faktor yang mempengaruhi, namun bukanlah yang utama. (5) Sementara unsur-unsur pembentuk kepribadian karakter, masih digunakan dan berpengaruh dalam penggambaran sifat karakter serta inspirasi antropomorfisme nya ke dalam visual desain karakter dan juga kemampuan karakter seperti yang dapat dilihat pada karakter Thorns.

\section{Kesimpulan}

Dapat disimpulkan bahwa, pada audiens gim berbasis menara pertahanan, khususnya Arknights, kemampuan karakter merupakan faktor pertama yang membuat sebuah karakter menjadi karakter favorit, disusul dengan desain karakter yang unik dengan mencampurkan teknik antropomorfisme moe pada desain maupun kemampuan karakter, kemudian disusul dengan sifat dan juga cerita karakter. Penggunaan hal-hal diluar tampilan fisik yang terkait dengan sumber antropomorfisme dalam pem- buatan cerita karakter juga dapat membuat keterkaitan lebih antara audiens dengan sumber inspirasi awalnya. Hasil studi ini juga dapat dikembangkan lebih lanjut dengan membandingkan antara karakter terpopuler yang sudah dilakukan dengan karakter kurang populer pada gim Arknights, untuk mengetahui kualitas antropomorfisme yang ada pada tiap desain karakter terkait.

\section{Referensi}

Amalinanda. (2018). Anthropomorphism and Animal Character in Art. https://journal.moselo.com/antro- 
pomorphism-and-animal-character-in-art-d26ob40e8bbf.

Andelina, I. R. (2020). Analisis Elemen Dalam Penciptaan Karakter Desain Di Dalam Ip Hypnosis Mic - Seiyuu X Rapper Project. Narada : Jurnal Desain Dan Seni, 7(2), 137. https://doi. org/10.22441/narada.2020.v7.i2.001

Andelina, I. R. (2021). Analisis Perubahan Desain Karakter Dalam Gim Final Fantasy VII Remake Berdasarkan Pendekatan Manga Matrix. Jurnal Dimensi DKV, 6(1), 75-92. http://dx.doi. org/10.25105/jdd.v6i1.9135.

https://www.bilibili.com/video/ BV1CA41137RC? fbclid = IwAR1WOczsuscesPxgVYi9Z2 KPCVizhvYspKjs39xcrsYgI9-b1bsEG39HzGQ

Baskoro, Wiku. (2016). Daftar Genre Video Game Beserta Penjelasannya. https://dailysocial.id/post/jenisgenre-game

Delgado-Ballester, E., Palazón, M., \& Peláez, J. (2020). Anthropomorphized vs objectified brands: which brand version is more loved? European Journal of Management and Business Economics, 29(2), 150-165. https://doi. org/10.1108/EJMBE-04-2019-0063

Luninareph. (2021). Arknights: New Operator Spotlight - Thorns. https:// gamepress.gg/arknights/operator-spotlight/arknights-new-operator-spotlight-thorns

Hikigaya, Nishima. (2020). Why is the Chinese Game Arknights Successful? https://pandayoo.com/2020/o8/17/ why-is-the-chinese-game-arknightssuccessful/

Julianto, Andy. (2019). Review Arknights - Bukan Sekadar Soal Harta, Gacha dan Wanita. https://gamebrott.com/ review-arknights-bukan-sekadar-gacha-tahta-dan-wanita.
Kaplan, Omer. (2019). Mobile gaming is a $\$ 68.5$ billion global business, and investors are buying in https:// techcrunch.com/2019/08/22/mobile-gaming-mints-money/

O'Brien, Daniel. (2020). Arknights: Should You Pull? The Glory of SilverAsh. https://gamepress.gg/arknights/should-you-pull/arknightsshould-you-pull-glory-silverash.

Hernández-Pérez, M. (2019). Japanese media cultures in Japan and abroad : transnational consumption of manga, anime, and media-mixes, Basel,Swit-zerland : MDPI, 2019

Putra, R. W., \& Muhdaliha, B. (2017). Analisis Visual Game Arena of Valor Sebagai Dasar Pengembangan Konsep Visual Game. Avant Garde, 5(2), 98. https://doi.org/10.36080/avg. v5i2.641

Rexan. (2020). A Look Into Arknights: Is It Worth the Hype? https://cellularnews.com/mobile-games/alook-into-arknights/

Subari, H.R. (2020). Arknights, the Gacha Game that's Popular in Otaku Community. https://duniagames.co.id/ discover/article/arknights-game-gacha/en

Violeta, K. N. (2020). Kajian Karakter Fiksi Arthur Pendragon Dalam Pendekatan Levels of Identity Dan Hubungannya Dengan Transmedia Storytelling. Ultimart: Jurnal Komunikasi Visual, 13(1), 24-34. https:// doi.org/10.31937/ultimart.v13i1.1356

Wahab, Taufiq., Nugroho, H.Y.S. (2020). Visualisasi Desain Karakter Satelit Palapa Sebagai Media Edukasi Melalui Komik. Jurnal ATRAT, 8(1). 24-38. 


\section{Literatur Daring:}

Arknights Youtube Official

Account, Coexistance. (2020) https:// www.youtube.com/watch?v=ZxYxOfkBgis

All Operators Popularity Ranking-Issue 6 [2nd Anniversary Version]. (2020). https://www.bilibili.com/ video/BV1CA41137RC?fbclid=IwAR1WOczsusces PxgVYigZ2 KPCVizhvYspKjs39xcrsYgI9-b1bsEG39HzGQ 